\title{
Effect of Inorganic Phosphate and Low pH on the Force-Velocity Relation of Single Skinned Skeletal Muscle Fibers Studied by Applying Parabolic Fiber Length Changes
}

\section{Ohno $\mathrm{T}^{1}$, Arao $\mathrm{T}^{2}$, Chaen $\mathrm{S}^{2}$ and Sugi $\mathrm{H}^{3 *}$}

${ }^{1}$ Department of Physiology, Jikei University School of Medicine, Tokyo, Japan

${ }^{2}$ Department of Biosciences, College of Humanities and Sciences, Nihon University, Tokyo, Japan

${ }^{3}$ Department of Physiology, School of Medicine, Teikyo University, Tokyo, Japan

\begin{abstract}
Although force-velocity $(P-V)$ relation is important to obtain insights into kinetics of actin-myosin interaction in muscle, determination of $P-V$ relation in skinned muscle fibers are difficult mainly due to gradual deterioration at the two cut fiber ends, which makes it impossible to obtain enough data points to construct $P$-V curve over the whole range of forces. In addition, determination of the maximum shortening velocity $V_{\max }$ by back extrapolation of limited data points to velocity axis is ambiguous because of the steep force versus velocity relation. To overcome these difficulties, we developed a novel method to obtain continuous $\mathrm{P}-\mathrm{V}$ curves over the whole range of forces from 0 to the maximum isometric force $\mathrm{Po}$, by applying length changes, with time course $\mathrm{L}=-\mathrm{kt}^{2}$, to $\mathrm{Ca}^{2+}$-activated skinned fibers, so that time derivative of length change, i.e. shortening velocity $V=-d L / d t=-2 k t$; namely, $V$ increased linearly with time $t$. By recording the resulting chane in force $P$, we could obtain continuous $\mathrm{P}-\mathrm{V}$ curve in one shot. Using the above method, we examined effect of high inorganic phosphate $(\mathrm{Pi})$ concentration and low pH (6.5) on $P$ - $V$ relation of skinned rabbit psoas muscle fibers at $20^{\circ} \mathrm{C}$ and at $5^{\circ} \mathrm{C}$ with the following results: (1) The P-V curves obtained exhibited a distinct hump at high force region $>0.5-0.6 P o$. The $P-V$ curves, deviated from rectangular hyperbola with forces $>\sim 0.2 P o$, did not change their shape appreciably by $\mathrm{Pi}$ and low $\mathrm{pH}$.; (2) $\mathrm{Pi}\left(30 \mathrm{mM}\right.$ ) reduced $\mathrm{Po}$ by $\sim 30 \%$ at $20^{\circ} \mathrm{C}$ and $\sim 45 \%$ at $5^{\circ} \mathrm{C}$; (3) $\mathrm{Low} \mathrm{pH}(6.5)$ showed no significant effect on $V_{\text {max }}$ at both 20 and $5^{\circ} \mathrm{C}$; and (4) $\mathrm{Pi}(30 \mathrm{mM})$ at low pH (6.5) reduced $\mathrm{Po}$ by $\sim 43 \%$ at $20^{\circ} \mathrm{C}$ and $\sim 45 \%$ at $5^{\circ} \mathrm{C}$. These results are discussed in relation of other published results.
\end{abstract}

Keywords: Muscle contraction; Force-velocity relation; Inorganic phosphate; Low pH; Skinned muscle fiber

\section{Introduction}

Muscle contraction results from cyclic attachment and detachment between myosin heads extending from myosin filaments and the corresponding sites on actin filaments, coupled with ATP hydrolysis. It is generally believed that myosin heads $(\mathrm{M})$ in the form of M-ADPPi first attach to actin filaments (A) to form A-M-ADP-Pi, and then perform power stroke, associated with release of products of ATP hydrolysis as A-M-ADP-Pi $\rightarrow \mathrm{A}-\mathrm{M}+\mathrm{ADP}+\mathrm{Pi}$. Biochemical studies on the actomyosin ATPase reaction steps indicate that $\mathrm{Pi}$ is the first to be released from A-M-ADP-Pi to initiate myosin head power stroke producing muscle contraction [1]. Being consistent with the above reaction scheme, increased Pi concentration (up to 25-30 mM) reduces the maximum isometric force $\mathrm{Po}$ in $\mathrm{Ca}^{2+}$-activated skinned muscle fibers [2-9], suggesting that high Pi concentration may cause product inhibition on the Pi release step. In contrast, at physiological ATP concentrations (millimolar range), high Pi concentration has no appreciable effect on the maximum shortening velocity $V_{\max }$ as well as the shape of force-velocity $(P-V)$ relation $[6,9]$.

On the other hand, it is well known that, after intense contractile activity, the ability of muscle to generate force and power decreases as a result of fatigue [10]. The onset of fatigue is caused by ATP hydrolysis products, i.e. ADP, $\mathrm{Pi}$ and $\mathrm{H}^{+}$[11]. Experiments with skinned muscle fibers have shown that low $\mathrm{pH}(\sim 6.5)$ has only a small effect on Po, but significantly reduces $V_{\max }[5,9]$. Because of the importance of studying the effect of increased $\mathrm{Pi}$ and low $\mathrm{pH}$ on in vitro ATP-dependent actinmyosin sliding have been performed intensively [12-16] at micromolar range of ATP concentration. Though their work is interesting, the experimental conditions of their experiments differ to far from the physiological condition in muscle. As a matter of fact, it has been pointed out that the results of in vitro experiments are not necessarily related to what is actually taking place in muscle [17].

Experiments with skinned muscle fibers have an inherent difficulty in obtaining reproducible results over a long period of time, since they are slowly deteriorating from their cut ends [18]. Due to the instability in condition at the two fiber ends, it is difficult to use the slack test, in which the maximum unloaded shortening velocity $V_{\max }$ is estimated from the time of force redevelopment after the fiber is slackened excessively [19]. In fact, Cooke and Pate [4] and Cooke et al. [9] encountered serious difficulties in using the slack test method for determining $V_{\text {max }}$. Instead, several investigators $[4,9,20,21]$ determined $V$ by back extrapolation of data points to the velocity axis based on the Hill equation, in which the relation between load (=force) $P$ and shortening velocity $V$ of contracting muscle are expressed as part of rectangular hyperbola as, $(P+a) V=b(P o-P)$, where $P o$ is the maximum isometric force and $a$ and $b$ are constants [20]. The extrapolation method is, however, unsuitable for accurate determination of $V_{\max }$ if the extremely steep slope of P-V curve in small load region is taken into consideration.

*Corresponding author: Haruo Sugi, Department of Physiology, School of Medicine, Teikyo University, Tokyo, Japan, Tel: +81484784079; E-mail: sugi@kyf. biglobe.ne.jp

Received: February 13, 2017; Accepted: February 24, 2017; Published: February 28, 2017

Citation: Ohno T, Arao T, Chaen S, Sugi H (2017) Effect of Inorganic Phosphate and Low pH on the Force-Velocity Relation of Single Skinned Skeletal Muscle Fibers Studied by Applying Parabolic Fiber Length Changes. J Nanomed Nanotechnol 8 : 428. doi: 10.4172/2157-7439.1000428

Copyright: ( 2017 Ohno T, et al. This is an open-access article distributed unde the terms of the Creative Commons Attribution License, which permits unrestricted use, distribution, and reproduction in any medium, provided the original author and source are credited. 
In addition, fitting experimental data points to the Hill equation is no longer valid by the following reasons: (1) $P-V$ relation in intact single muscle fibers has been shown to be double hyperbolic in shape [21], so that P-V curve deviates from hyperbola in high force region, indicating that the Hill equation cannot be applied cover the whole range of forces from zero to $P o$; (2) Similar deviation of $P$ - $V$ curve from hyperbola in high force region has been confirmed in intact single muscle fibers [22]; and also in skinned muscle fibers [17,23,24]. These results imply that the Hill equation is only a first order approximation of experimental results obtained from whole muscles, which contain many different types of muscle fibers, connective tissues and blood vessels, and is therefore not useful in obtaining insights into the mechanism of muscle contraction.

The present experiments were undertaken to study the effect of $\mathrm{Pi}$ and $\mathrm{pH}$ on the $P-V$ relation, especially on the value of $V_{\text {max }}$ in single skinned muscle fibers, using a novel method to directly measure $V_{\text {max }}$ by applying parabolic decrease in fiber length and recording the resulting changes in shortening velocity $V$ and force $P$. Experiments were only made at physiological ATP concentration, since we are primarily interested in the actin-myosin interaction in muscle under physiological conditions, but not under conditions differing too far from 3D myofilament lattice structure in muscle.

\section{Materials and Methods}

\section{Skinned muscle fiber preparation}

White male rabbits weighing 2 to $2.5 \mathrm{~kg}$ were killed by injection of sodium pentobarbital $(50 \mathrm{mg} / \mathrm{kg})$ into the ear vein, and psoas muscle was dissected from the animals. The animals were treated in accordance with the Guiding Principles for the Care and Use of Animals in the field of Physiological Sciences, published by the Physiological Society of Japan. The protocol was approved by the Teikyo University Animal Care Committee (protocol \#07-050). Glycerol-extracted muscle fiber strips were prepared from psoas muscle as described by [24]. Single muscle fibers (diameter, 50-100 $\mu \mathrm{m}$ ) were dissected from fiber strips, and mounted horizontally in an experimental chamber $(400 \mu \mathrm{l})$ between a force transducer (Akers 801, Aksjeselkapet, Holten, Norway) and a servomotor (Aurora Scientific Inc., Aurora, Canada) by gluing both ends with collodion. The servomotor contained a displacement transducer (differential capacitor) sensing motor arm position. Further details of experimental apparatus have been described elsewhere [24]. The fibers were kept at slack length $L o(\sim 2 \mathrm{~mm})$ at a sarcomere length of $2.4 \mu \mathrm{m}$, measured with optical diffraction by $\mathrm{He}-\mathrm{Ne}$ laser light. Relaxing solution contained $125 \mathrm{mM} \mathrm{KCl}, 5.9 \mathrm{mM} \mathrm{MgCl}_{2}, 2.4 \mathrm{mM}$ ATP, $5 \mathrm{mM}$ EGTA, 20 mM Pipes ( $\mathrm{pH}$ 7.0). Contracting solution was prepared by adding $5 \mathrm{mM} \mathrm{CaCl}_{2}$ to relaxing solution to maximally activate the fibers. Low $\mathrm{pH}$ solutions ( $\mathrm{pH}$ 6.5) were prepared by adding $\mathrm{HCl}$. Temperature of solutions was kept at $20^{\circ} \mathrm{C}$ with a thermoelectric device. Solutions were exchanged by draining and refilling the experimental chamber with a micropipette.

\section{Determination of force-velocity relation in $\mathrm{Ca}^{2+}$-activated skinned muscle fibers by applying parabolic decrease in fiber length}

In the present study, we used a novel method to obtain whole range of $\mathrm{P}-\mathrm{V}$ relation in one shot in the following way. The servo motor was operated in a length control mode to apply a slow decrease in fiber length $L$ (duration, 50-500 ms) to a $\mathrm{Ca}^{2+}$-activated muscle fiber generating the maximum isometric force Po. The shape of the slow decrease in $L$ was part of upside-down parabola, so that $L$ decreased with the square of time $t$, as $L=-k t^{2}$, where $k$ is a constant. The velocity of decrease in fiber length $V$ at time $t$ is therefore, $\mathrm{V}=d L / d t=-2 k t$; namely, the value of $V$ increases linearly with time $t$. The parabolic length command signal was generated by an arbitrary function generator (Aurora Scientific Ic., Aurora, Canada), and fed into the servo motor control circuit.

Figure 1 shows an example of simultaneous recordings of the parabolic decrease in fiber length $L$ (upper record), the velocity of fiber shortening $V$, decreasing linearly with time (middle record), and the resulting decrease in force $P$ (lower record) in the fiber. As illustrated by vertical and horizontal broken lines, $V=0$ when $P=P o$, and $V=V$, when $P=0$. Consequently, the force record per se constitutes the forcevelocity $(P-V)$ relation, since the time $t$ axis in Figure 1 can be velocity $V$ axis. Thus, a continuous $\mathrm{P}-\mathrm{V}$ curve covering the whole range of $P$ from 0 to $P o$ can be obtained by one shot, i.e. by applying a single parabolic length change to the fiber. The above method, using the parabolic changes in fiber length, is technically easier compared to the ramp force decrease method used in our previous experiments [17,23,24]. Reproducible $P-V$ curves were obtained by repeated application of parabolic length changes to the same muscle fiber up to several times, proving that, by this method, difficulties in determining $P-V$ curve, including $V_{\max }$ in skinned fibers are overcome. Both the value of $V_{\max }$ and the shape of $P-V$ curve were not affected by changing the duration of parabolic change in $L$ from 50 to $500 \mathrm{~ms}$.

\section{Results}

\section{Features of force-velocity relation in standard experimental condition}

We examined to what extent $P-V$ curves obtained by applying parabolic decrease in fiber length (Figure 1) deviates from rectangular hyperbola as predicted Hill equation. Figure 2 shows linearized Hill equation plot, in which the quantity. $(1-P / P o) / V$ is plotted against relative force $(P / P o)$, both $P$ and $V$ values being taken from $P$ - $V$ curve shown in Figure 1. If the present $\mathrm{P}-\mathrm{V}$ curve fits Hill equation, all $P-V$ data points should fall on a straight line. As can be seen in the figure, only data points $<\sim 0.2 P o$ fell on the straight line, indicating that the

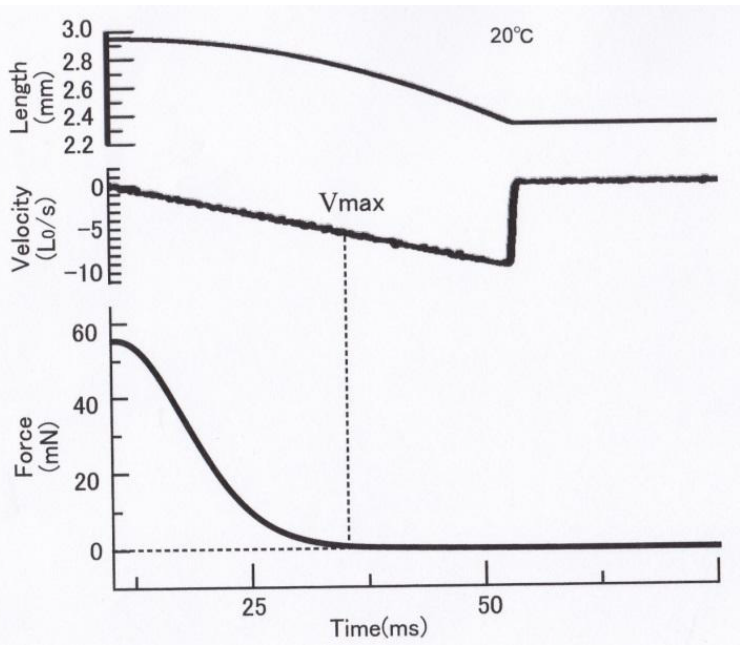

Figure 1: Determination of force-velocity $(P-V)$ relation by one shot by applying parabolic decrease in fiber length to isometrically contracting single skinned muscle fibers. (Upper record) Time course of parabolic decrease in fiber length, $L=-k t^{2}$. (Middle record) Time course of linear decrease of fiber shortening velocity, $-d L / d t=-2 k$ (Lower record) Time course of the resulting decrease of force in the fiber. For further explanations, see text. 


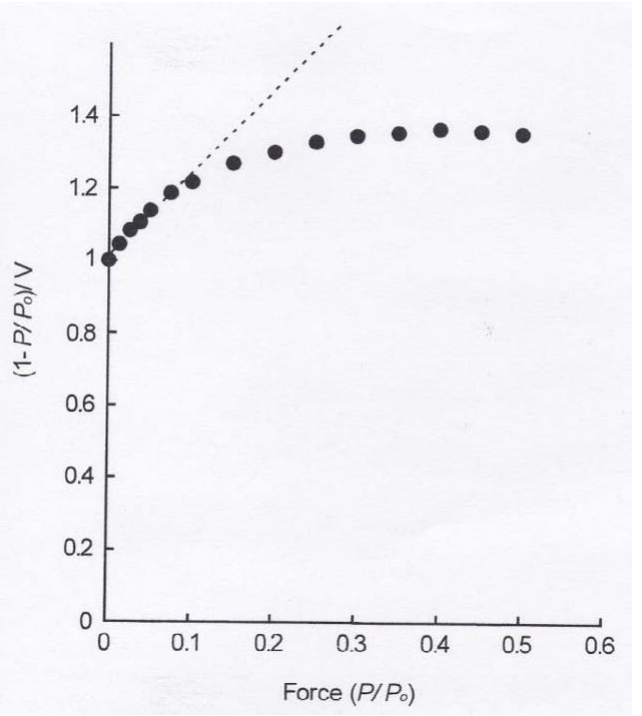

Figure 2: Linearized Hill equation plot of data points selected on the continuous $P-V$ curve shown in Figure 1 . The quantity $(1-P / P O) V$ are plotted against force $(P / P o)$. Note that the data points fit to the Hill equation only for forces $<\sim 0.2 P o$

$\mathrm{P}-\mathrm{V}$ curves determined in the present study deviates from hyperbola predicted by Hill equation at forces $>\sim 0.2 P o$. It should be noted that similar deviation of $\mathrm{P}-\mathrm{V}$ curve from Hill equation at forces $>\sim 0.2 \mathrm{Po}$ has been reported by Julian et al. [25], who obtained P-V curves in intact muscle fibers by using length clamp and force clamp techniques.

Figure 3 shows averaged force-velocity $(P-V)$ curves obtained from six different muscle fibers at $20^{\circ} \mathrm{C}$ and at $5^{\circ} \mathrm{C}$ in the standard experimental condition $(\mathrm{Pi}, 0 \mathrm{mM} ; \mathrm{pH}, 7.0)$. Both velocities and forces (=loads) are expressed relative to the maximum values, respectively. In agreement with the previous reports, in which the $P-V$ curves were obtained by applying ramp decreases in force from $P o$ to 0 to $\mathrm{Ca}^{2+}$ activated fibers $[17,23,24]$, the $P$ - $V$ curves obtained in the present study also showed a distinct hump in the high load (=force) region above 0.5-0.6 Po. The maximum isometric force Po was $142 \pm 49 \mathrm{kN} / \mathrm{m}^{2}$ (mean $\pm \mathrm{SD}, \mathrm{n}=6)$ at $20^{\circ} \mathrm{C}$, and $104 \pm 40 \mathrm{kN} / \mathrm{m}^{2}(\mathrm{n}=6)$ at $5^{\circ} \mathrm{C}$. While the maximum shortening velocity $V_{\text {max }}$ was $0.77 \pm 0.14 \mathrm{Lo} / \mathrm{s}(\mathrm{n}=6)$ at $20^{\circ} \mathrm{C}$, and $0.49 \pm 0.14 \mathrm{Lo} / \mathrm{s}$ at $5^{\circ} \mathrm{C}$. The values of $P o$ and $V_{\max }$ in the standard experimental condition are not much different from the reported values, if the difference in temperature is taken into consideration.

Effect of high inorganic phosphate concentration on forcevelocity relation of skinned muscle fibers

Figure 4 are averaged $P$ - $V$ curves obtained from six different muscle fibers in the presence of $30 \mathrm{mM} \mathrm{Pi}(\mathrm{pH}, 7.0)$ at $20^{\circ} \mathrm{C}$ and at $5^{\circ} \mathrm{C}$, In this and the subsequent Figures 5 and 6, both $P$ and $V$ values are expressed relative to the maximum value obtained in control conditions $(\mathrm{Pi}$ $0 \mathrm{mM}, \mathrm{pH}$ 7.0) together with control $P-V$ curves (broken lines), the control $P-V$ curves obtained at standard experimental condition, are also shown (broken lines). In this and subsequent Figures 5 and 6, the shape of $P-V$ curves did not differ appreciably from control $P-V$ curves in the presence of $30 \mathrm{mM} \mathrm{Pi}$, except for the $\mathrm{Pi}$-induced prominent decrease in the vaule of $P o$. This may be taken to indicate that basic kinetic properties of cyclic actin-myosin interaction are not seriously influenced by the factors examined in the present study.

In the presence of $30 \mathrm{mM} \mathrm{Pi}$, the average value of $P o$ was $105 \pm 49$
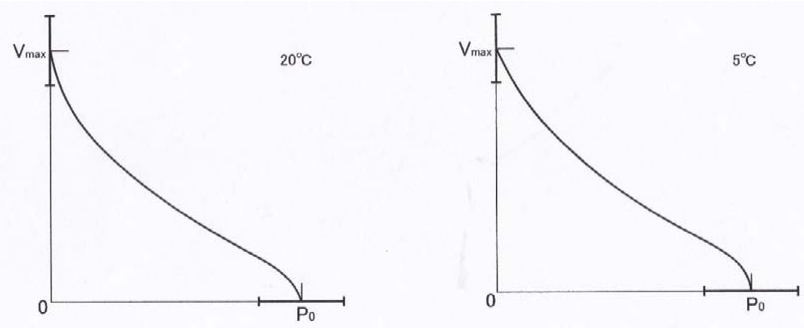

Figure 3: Averaged $P-V$ relations obtained in the standard (control) experimental condition ( $\mathrm{Pi} 0 \mathrm{mM}, \mathrm{pH} 7.0$ ) from six fibers at $20^{\circ} \mathrm{C}$ and from six fibers at $5^{\circ} \mathrm{C}$. Both velocities and forces are expressed relative to the maximum shortening velocity $V \max$ and the maximum isometric force $P_{0}$, respectively. In this and Figures 4-6, vertical and horizontal bars on velocity and force axes indicate SD of Vmax and Po values, respectively.
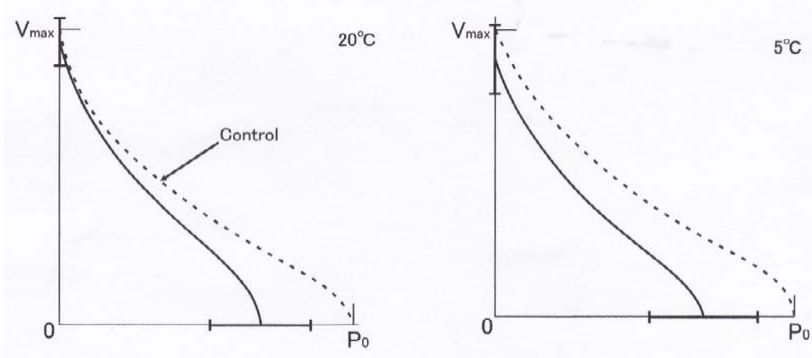

Figure 4: Averaged $P-V$ relations in the presence of $30 \mathrm{mM} \mathrm{Pi}(\mathrm{pH} 7.0)$ obtained from 6 fibers at $20^{\circ} \mathrm{C}$ and from 6 fibers at $5^{\circ} \mathrm{C}$. In this and Figures 5 and 6 , both velocities and forces are expressed relative to control Vmax and $P o$ values obtained in control experimental condition ( $\mathrm{Pi} 0 \mathrm{mM}, \mathrm{pH} 7.0$ ), respectively, while control $\mathrm{P}-\mathrm{V}$ curves are also shown by broken lines.
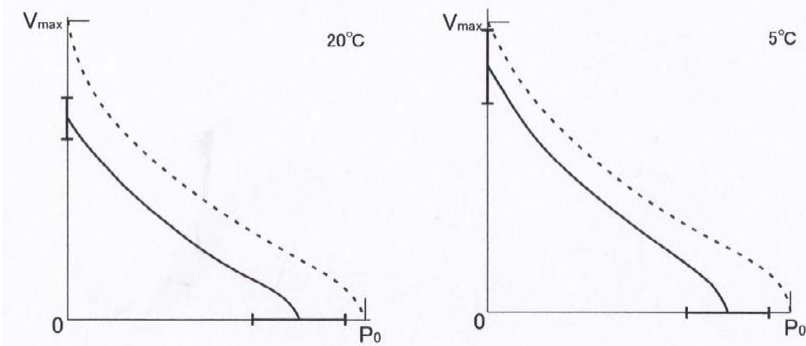

Figure 5: Averaged $P-V$ relations at low $\mathrm{pH}(\mathrm{Pi} 0 \mathrm{mM}, \mathrm{pH}$ 6.5), obtained from six fibers at $20^{\circ} \mathrm{C}$ and from six fibers at $5^{\circ} \mathrm{C}$.
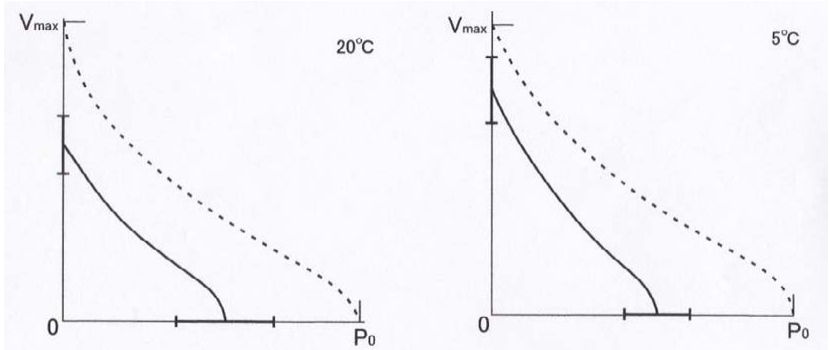

Figure 6: Averaged $P-V$ relations in the presence of $30 \mathrm{mM} \mathrm{Pi}$ and at low $\mathrm{pH}$ (6.5), obtained from six fibers at $20^{\circ} \mathrm{C}$ and from six fibers at $5^{\circ} \mathrm{C}$. 
$\mathrm{kN} / \mathrm{m}^{2}(\mathrm{n}=6)$ at $20^{\circ} \mathrm{C}$, and $79 \pm 39 \mathrm{kN} / \mathrm{m}^{2}(\mathrm{n}=6)$ at $5^{\circ} \mathrm{C}$, being $\sim 30 \%$ and $45 \%$ smaller than the corresponding control values in standard experimental condition ( $\mathrm{Pi}, 0 \mathrm{mM}, \mathrm{pH}, 7.0)$. The prominent $\mathrm{Pi}$-induced reduction of $P o$ agrees with all the previous reports already listed in Introduction.

On the contrary, the average value of $V_{\max }$ was $0.77 \pm 0.15 \mathrm{Lo} / \mathrm{s}$ (mean $\pm \mathrm{SD}, \mathrm{n}=6)$ at $20^{\circ} \mathrm{C}$, and $0.44 \pm 0.12 \mathrm{Lo} / \mathrm{s}(\mathrm{n}=6)$ at $5^{\circ} \mathrm{C}$ in the presence of $30 \mathrm{mM} \mathrm{Pi}$, being the same as that of control value at $20^{\circ} \mathrm{C}$ and only $\sim 10 \%$ smaller than the control values at $5^{\circ} \mathrm{C}$. The $10 \%$ decrease of $V_{\max }$ at $5^{\circ} \mathrm{C}$ was not statistically significant ( $t$ test, $\mathrm{P}<0.01$ ), indicating that, in contrast to the value of $P o$, the value of $V_{\max }$ was not significantly influenced by $30 \mathrm{mM}$ Pi. This result agrees with the report of Cooke et al. [9].

\section{Effect of low $\mathrm{pH}$ on force-velocity relation of skinned muscle fibers}

The averaged $P-V$ curves at low $\mathrm{pH}(\mathrm{Pi}, 0 \mathrm{mM}, \mathrm{pH}, 6.5)$ are presented in Figure 5. The average value of $P o$ at low $\mathrm{pH}$ was $111 \pm$ $45 \mathrm{kN} / \mathrm{m}^{2}($ mean $\pm \mathrm{SD}, \mathrm{n}=6)$ at $20^{\circ} \mathrm{C}$, and $80 \pm 29 \mathrm{kN} / \mathrm{m}^{2}(\mathrm{n}=6)$ at $5^{\circ} \mathrm{C}$, being $21 \%$ and $35 \%$ smaller than the corresponding control values. The decrease of $P o$ at low $\mathrm{pH}$ was statistically significant $(t$ test, $\mathrm{P}<0.05)$, being consistent with the report of Cooke et al. [9] on skinned fibers.

Meanwhile, the average value of $V_{\max }$ at low $\mathrm{pH}$ was $0.70 \pm 0.13$ $\mathrm{Lo} / \mathrm{s}($ mean $\pm \mathrm{SD}, \mathrm{n}=6)$ at $20^{\circ} \mathrm{C}$, and $0.43 \pm 0.13(\mathrm{n}=6)$ at $5^{\circ} \mathrm{C}$, being $9 \%$ and $12 \%$ smaller than the corresponding control values. The decrease of $V_{\text {max }}$ at low $\mathrm{pH}$ was, however, not statistically significant because of much larger scatter in the values of $V_{\text {max }}$ compared to that in the values of $\mathrm{Po}$, indicating that low $\mathrm{pH}$ has no significant effect on the value of $V_{\text {max }}$, though $\mathrm{V}_{\max }$ exhibited a tendency to decrease at low $\mathrm{pH}$. This result disagrees with the report of Cooke et al. [9] that $V_{\max }$ skinned fibers is reduced by $25-30 \%$ at low $\mathrm{pH}$. The disagreement in the effect of low $\mathrm{pH}$ may be due, at least in part, to the inaccurate measurement of $V_{\max }$ by fitting data points to Hill equation.

\section{Combined effects of high Inorganic phosphate concentration and low $\mathrm{pH}$ on force-velocity relation of skinned muscle fibers}

Figure 6 shows the averaged $P-V$ curves in the presence of $30 \mathrm{mM}$ $\mathrm{Pi}$ at low $\mathrm{pH}$ (6.5). The average value of $P o$ was $80 \pm 48 \mathrm{kN} / \mathrm{m}^{2}$ (mean $\pm \mathrm{SD}, \mathrm{n}=6)$ at $20^{\circ} \mathrm{C}$, and $57 \pm 23 \mathrm{kN} / \mathrm{m}^{2}(\mathrm{n}=6)$ at $5^{\circ} \mathrm{C}$, being $43 \%$ and $45 \%$ smaller than the corresponding control values. The average value of $V_{\max }$ was $0.62 \pm 0.18 \mathrm{Lo} / \mathrm{s}$ (mean $\pm \mathrm{SD}, \mathrm{n}=6$ ) at $20^{\circ} \mathrm{C}$, and $0.38 \pm 0.12$ $L o / s(\mathrm{n}=6)$ at $5^{\circ} \mathrm{C}$, being $21 \%$ and $22 \%$ smaller than the corresponding control values. In both $P o$ and $V_{\max }$, all these differences were statistically significant $(t$ test, $\mathrm{P}<0.01)$.

\section{Discussion}

Figures 7 and 8 show histograms summarizing the effect of high $\mathrm{Pi}$ concentration and low $\mathrm{pH}$ on $\mathrm{Po}$ and $V_{\max }$ in $\mathrm{Ca}^{2+}$ activated single skinned muscle fibers. In general, $V_{\max }$ values show much wider range of variation than Po values. In the report of Edman [21] who carefully estimated $V_{\max }$ by using slack test and controlled length changes, the range of SD amounts $\sim \pm 30 \%$ of the mean value of $V_{\max }$. The wide scatter of $V_{\max }$ from fiber to fiber seems to result from some intrinsic property of cyclic actin-myosin interaction under small loads. The function of skeletal muscle in animal body is to generate isometric force or to shorten under heavy inertial load, but not to shorten under constant eternal load. In this sense, isotonic shortening is a highly unusual

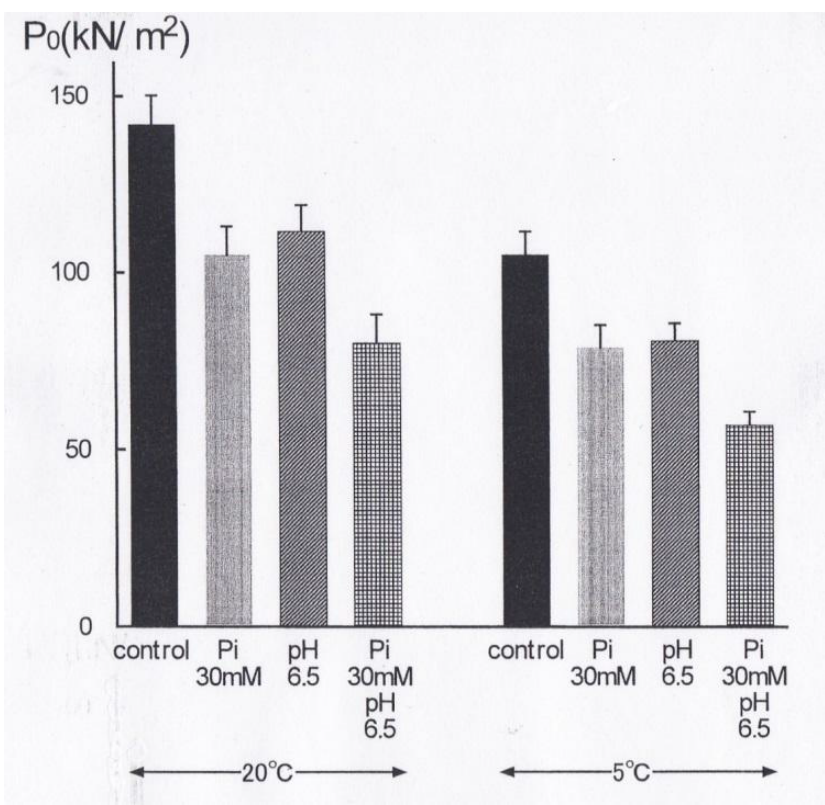

Figure 7: Histograms of mean $P o$ values with $\pm S D$, summarizing the effect of high $\mathrm{Pi}(30 \mathrm{mM})$ and low $\mathrm{pH}(6.5)$ on the value of $P o$, including their combined effect. *Significantly different from control value, $\mathrm{P}<0.01$.

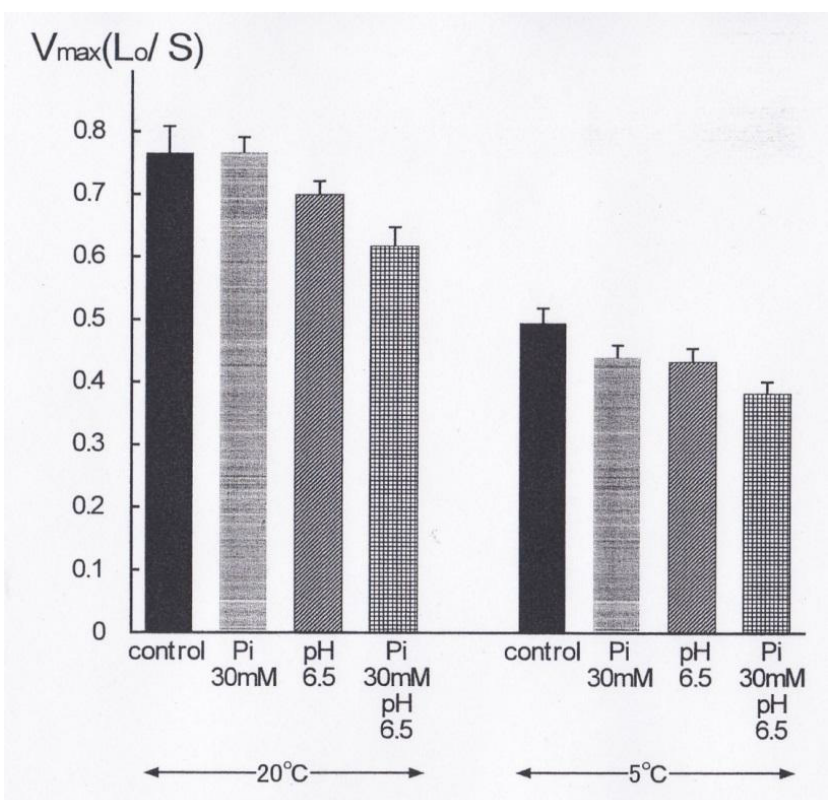

Figure 8: Histograms of mean $V \max$ values with $\pm S D$, summarizing the effect of low $\mathrm{pH}(6.5)$ on the value of $V \max$, including their combined effect. 'Significantly different from control value, $\mathrm{P}<0.05$

mode of muscle performance. In the Huxley contraction model [26], isometric force generation results from cyclic actin-myosin interaction localized in the region where myosin heads exert positive force, while during isotonic shortening force (equal to external load) in muscle is the difference between positive and negative forces at positive and negative force regions.

As the Huxley contraction model only deals with steady isotonic shortening, but not transition process from isometric to isotonic 
Citation: Ohno T, Arao T, Chaen S, Sugi H (2017) Effect of Inorganic Phosphate and Low pH on the Force-Velocity Relation of Single Skinned Skeletal Muscle Fibers Studied by Applying Parabolic Fiber Length Changes. J Nanomed Nanotechnol 8: 428. doi: 10.4172/2157-7439.1000428

Page 5 of 5

conditions, this model cannot explain the transient oscillatory changes in shortening velocity preceding subsequent constant velocity shortening $[27,28]$. In fact, there are many possible explanations for the transient changes in shortening velocity not only in terms of rate constants for making and breaking actin-myosin linkages, but also in terms of A-M linkage breaking forced by muscle shortening per se [29]. It seems possible that the kinetics of cyclic actin-myosin interaction is much more complicated than is generally assumed, and kinetics of actin-myosin interaction is non-uniform from region to region in myofilament lattice. The ineffectiveness of high $\mathrm{Pi}$ concentration and Low $\mathrm{pH}$ gives at present no definite information about the complicated mechanism underlying $V_{\text {max }}$. Much more experimental work is needed on the behavior of isotonically shortening muscle fibers.

Meanwhile, the well-known inhibitory effect of high $\mathrm{Pi}$ concentration, which is confirmed in the present study, has already been explained by many authors, already listed in Introduction, as being due to product inhibition of Pi-releasing step, A-M-ADP-Pi $\rightarrow \mathrm{A}-\mathrm{M}-\mathrm{ADP}+\mathrm{Pi}$, associated with weak to strong binding transition of A-M linkages [1]. At present, we can add no additional idea to the above explanation.

With respect to the inhibitory effect of low $\mathrm{pH}$ on $\mathrm{Po}$, no clear explanation has been given up to the present time [9]. Based on in vitro motility experiments, Debald et al. $[15,16]$ suggest that low $\mathrm{pH}$ and high Pi modify rate of breaking of A-M linkages, and can cause inhibition of either $P_{o}$ and $V_{\max }$ depending on experimental conditions. As pointed out by Sugi et al. [17], however, the state of contractile proteins in vitro experiments differs too far from those in muscle and their explanation is far from being conclusive. The combined effect of high $\mathrm{Pi}$ and low $\mathrm{pH}$ to reduce both $\mathrm{Po}$ and $V_{\max }$ agrees with the results of Cooke et al. [9] and Nelson and Fitts [30], giving information about the mechanism underlying muscle fatigue.

\section{Acknowledgement}

We dedicate this paper to the late Professor Takakazu Kobayashi, who suddenly passed away in July, 2016. Our thanks are also due to Aurora Scientific Inc. for supporting our present work.

\section{Author Contributions}

H.S. designed and performed experiments, and wrote the manuscript. T.O. T.A. and S.C. designed and performed experiments.

\section{Competing Financial Interests}

The authors declare no financial interests.

\section{References}

1. Lymn RW, Taylor EW (1971) Mechanism of adenosine triphosphate hydrolysis by actomyosin. Biochemistry 16: 4617-4624

2. Ruegg JC, Schadler M, Steiger GJ, Millar G (1971) Effects of inorganic phosphate on the contractile mechanism. Pflugers Archiv 325: 359-364.

3. Hibbard MG, Danzig JA, Trentham DR, Goldman YE (1985) Phosphate release and force generation in skeletal muscle fibers. Science 228: 1317-1319.

4. Cooke R, Pate $E$ (1985) The effect of ADP and phosphate on the contraction of muscle fibers. Biophys J 48: 789-798.

5. Kentish JC, Nayler WG (1979) The influence of $\mathrm{pH}$ and Ca2+-regulated ATPase of cardiac and white skeletal myofibrils. J Molec Cell Cardiol 11: 611-617.

6. Nosek TM, Fender KY, Godt RE (1987) It is deprotonated inorganic phosphate that dipresses force in skinned skeletal muscle fibers. Science 236: 191-193.

7. Brozovich FV, Yates LD, Gordon AM (1988) Muscle force and stiffness during activation and relaxation. Implications for the actomyosin ATPase. J Gen Physiol 91: 399-420.
8. Chase PB, Kushmerick MJ (1988) Effects of $\mathrm{pH}$ on contraction of rabbit fast and slow skeletal muscle fibers. Biophys J 53: 935-946

9. Cooke R, Franks K, Luciani GB, Pate E (1988) The inhibition of rabbit skeleta muscle contraction by hydrogen ions and phosphate. J Physiol 395: 77-97.

10. Westerblad H, Bruton JD, Lännergren J (1997) The effect of intracellular pH on contractile functions intact, single fibres mouse muscle declines with increasing temperature. J Physiol 500: 193-204.

11. Fitts RH (1994) Cellular mechanisms of muscle fatigue. Physiol Rev 74: 49-94

12. Debold PE, Dave H, Fitts RH (2004) Fiber type and temperature dependence inorganic phosphate: implications of fatigue. Am J Physiol Cell Physiol 287: C673-C681.

13. Hooft AM, Maki EJ, Cox KK, Baker JE (2007) An accelerated state of myosinbased actin motility. Biochemistry 46: 3513-3520.

14. Amrute-Nayak M, Antognozzi M, Scholz T, Kojima H, Brenner B (2008) Inorganic phosphate binds to the empty nucleotide binding pocket of conventional myosin II. J Biol Chem 283: 3773-3781

15. Debold EP, Beck SE, Warshow DM (2008) Effect of low pH on single muscle myosin mechanics and kinetics. Am J Physiol Cell Physiol 295: C173-C179.

16. Debold EP, Turner MA, Stout JC, Walcott S (2011) Phosphate enhances myosin-powered actin filament velocity under acidic conditions in a motility assay. Am J Physiol Regul Integr Comp Physiol 300: R1401-R1408.

17. Sugi H, Chaen S, Kobayashi T, Abe T, Kimura K, et al. (2014) Definite differences between in vitro actin-myosin sliding and muscle contraction as revealed using antibodies to myosin head. Plos One 9: e93272.

18. Brenner B (1998) Muscle mechanics II: Skinned muscle fibres. In Current Methods in Muscle Physiology, ed Sugi H, Oxford University Press, Oxford 33-69.

19. Edman KAP (1979) The velocity of unloaded shortening and its relation to sarcomere length and and isometric force in vertebrate muscle fibres. J Physiol 291: 143-159.

20. Hill AV (1938) The heat of shortening and the dynamic constants of muscle. Proc Roy Soc B126: 136-195.

21. Edman KAP (1988) Double-hyperbolic force-velocity relation in frog muscle fibres. J Physiol 404: 301-321.

22. Iwamoto H, Sugaya R, Sugi H (1990) Force-velocity relation of frog skeletal muscle fibres shortening under constantly increasing load. J Physiol 422: 185202.

23. Sugi H, Abe T, Kobayashi T, Chaen S, Ohnuki Y, et al. (2013) Enhancement of force generated by individual myosin heads in skinned rabbit psoas muscle fibers at low ionic strength. Plos One 8: e63658.

24. Sugi H, Kobayashi T, Gross T, Noguchi K, Karr T, et al. (1992) Contraction characteristics and ATPase activity of skinned muscle fibers in the presence of antibody to myosin subfragment-2. Proc Natl Acad Sci USA 89: 6134-6137.

25. Julian FJ, Rome LC, Stephenson DG, Striz S (1986) The naximum speed of shortening in living and skinned frog muscle fibres. J Physiol 370: 181-199.

26. Huxley AF (1957) Muscle structure and theories of contraction. Prog Biophys Biophys Chem 7: 255-318.

27. Civan MM, Podolsky RJ (1966) Contraction kinetics of striated muscle fibres following quick changes in load. J Physiol 184: 511-534.

28. Sugi $H$, Tsuchiya $T$ (1981) Isotonic velocity transients in frog muscle fibres following quick changes in load. J Physiol 319: 239-252.

29. Podolsky RJ, Nolan AC (1973) Muscle contraction transients, cross-bridge kinetics, and the Fenn effect. Cold Spring Harbor Symp Quant Biol 37: 661-668.

30. Nelson CR, Fitts RH (2014) Effects of low pH and elevated inorganic phosphate on the pCa-force relantionship in single muscle fibers at near-physiological temperatures. Am J Physiol Cell Physiol 306: C670-C678. 